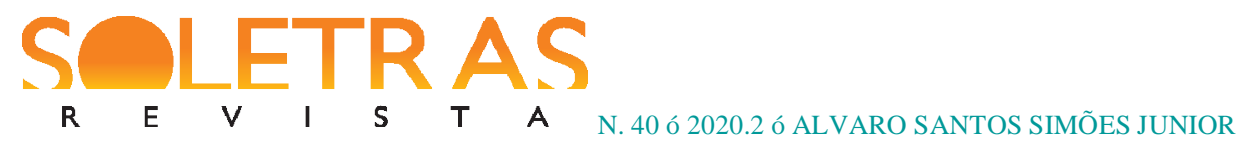

\title{
Os simples, de Guerra Junqueiro, e a imprensa carioca
}

\begin{abstract}
Alvaro Santos Simões Junior ${ }^{1}$
Resumo: De 1890 a 1893, ocorreu em Portugal um intenso movimento literário como resultado da assimilação das ideias decadentistas-simbolistas emanadas de França. Publicaram-se nesse período dezesseis obras com tendências inovadoras. No Rio de Janeiro, a imprensa acompanhou sem muito entusiasmo as notícias e as polêmicas motivadas pelas publicações e atitudes de Eugênio de Castro, Antônio Nobre e Alberto de Oliveira, entre outros jovens escritores. No entanto, a obra decadentistasimbolista que mais despertou interesse dos jornais e revistas cariocas foi Os simples, livro de poesia lírica publicado pelo veterano Guerra Junqueiro em 1892. A análise de notícias, resenhas e artigos sobre essa obra possibilita compreender um pouco melhor o modo por que se deu a assimilação do decadentismo-simbolismo no Brasil.
\end{abstract}

Palavras-chave: Decadentismo. Simbolismo. Os simples. Guerra Junqueiro.

De 1890 a 1893, ocorreu em Portugal um intenso movimento literário como resultado da assimilação das ideias decadentistas-simbolistas emanadas de França. Considerando resenhas, crônicas e notícias publicadas na imprensa carioca, pode-se afirmar que foi muito modesta a repercussão desse movimento no Brasil. As obras Oaristos (1890) e Horas (1891), de Eugênio de Castro, que se gabava de ser o introdutor das ñideias modernasò em terras portuguesas, foram praticamente ignoradas, se se leva em consideração, comparativamente, o volume de textos publicados sobre essas obras na imprensa de Porto, Coimbra e Lisboa. Melhor sorte teve o livro Só, publicado por Antônio Nobre chez Léon Vanier, editor parisiense dos principais poetas decadentistas-simbolistas, embora seu surgimento não motivasse a publicação de muitos textos na imprensa periódica do Rio de Janeiro.

Porém, foi relativamente bem-sucedido o veterano Guerra Junqueiro, cujo livro intitulado Os simples foi alvo de notícias e comentários de jornalistas e escritores brasileiros e analisado por correspondentes estrangeiros de alguns jornais cariocas. Apesar de publicar a

\footnotetext{
${ }^{1}$ Doutor em Letras pela Universidade Estadual Paulista Júlio de Mesquita Filho (2001) e pós-doutorado pela Universidade de Lisboa (2011). Atualmente é professor assistente doutor II da Faculdade de Ciências e Letras de Assis (UNESP). Tem experiência na área de Letras, com ênfase em Literatura Brasileira. Brasil. São Paulo. Email: simoes@ femanet.com.br Orcid: https://orcid.org/0000-0002-5269-7108.
} 


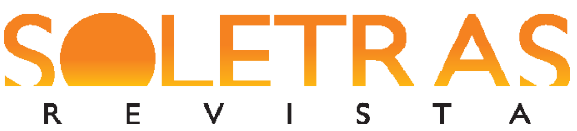

sua poesia lírica cerca de dois meses depois do Só, de Nobre, Guerra Junqueiro, que já era muito conhecido por suas sátiras A morte de D. João (1874), A velhice do Padre Eterno (1885) e Finis patriae (1890), pelo comovente opúsculo A fome no Ceará (1877) e também por A musa em férias (1879), passou a ser considerado pelos brasileiros o principal representante do chamado nefelibatismo. $\mathrm{O}$ exame dos textos publicados na imprensa carioca a respeito de Os simples talvez possa evidenciar o que os brasileiros entenderam por poesia nefelibata no final do século XIX.

Curiosamente foi um jornal carioca, O Tempo, o primeiro a anunciar em 14 de setembro de 1891 a publicação do novo livro de Guerra Junqueiro, cujo título informou ser Líricas (POR TODO, 1891, p. 1). Em Portugal, o primeiro anúncio ocorreria apenas em 15 de dezembro do mesmo ano, nas Balas... de Papel, de Lisboa ${ }^{2}$ (GOMES; SERTÓRIO, 1891, p. 10). A venda na livraria Garnier (v. figura 1) verificou-se com pequeno intervalo em relação ao início das vendas nas livrarias portuguesas em 29 de maio de $1892 .{ }^{3}$ Em 18 de junho, cronista das Novidades já dava conta de que os exemplares então disponíveis na famosa livraria carioca se haviam esgotado (MARCOS, 1892, p. 1). Verifica-se, portanto, que no final do século XIX o mercado editorial brasileiro tinha perfeitas condições infraestruturais de acompanhar de perto o europeu. Os intelectuais brasileiros podiam, assim, permanecer atualizados em relação às publicações estrangeiras mais importantes.

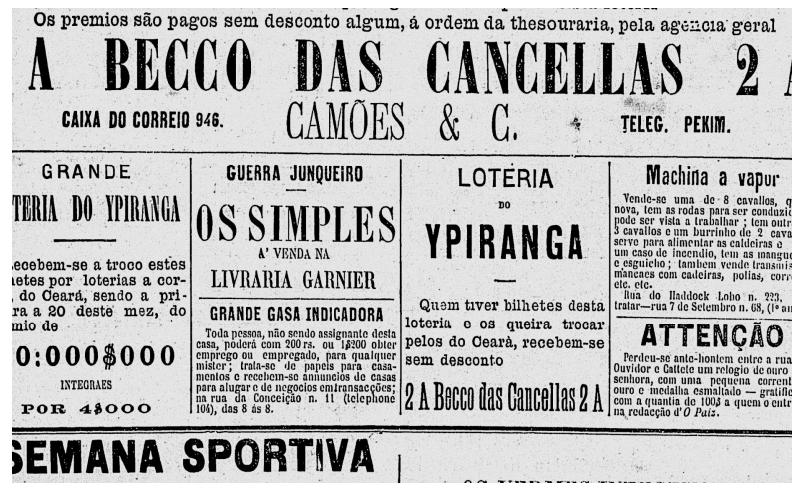

Fig.1 Anúncio do livro Os simples publicado na sexta e última página do diário $O$ País em 16 de setembro de 1892.

\footnotetext{
${ }^{2}$ Todas as considerações sobre precedências e quantidade de publicações devem ser relativizadas por duas variáveis: 1) possível inadvertência do pesquisador que compulsou quantidade significativa de periódicos e, principalmente, 2) lacunas das coleções dos jornais e revistas, que chegaram mutiladas e/ou com números faltantes aos nossos dias.

${ }^{3}$ Nesse dia, vários jornais portugueses trouxeram anúncio emoldurado da obra.
} 


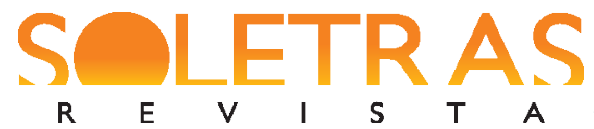

N. 40 ï 2020.2 ï ALVARO SANTOS SIMÕES JUNIOR

O citado cronista das Novidades, que se escondia sob o pseudônimo D. Marcos, foi o primeiro, em terras fluminenses, a emitir opinião sobre Guerra Junqueiro, cujos versos representavam, para ele, a ñarte manejada com todas as suas exigências de forma, com toda a sua filosofia moderna, encantando os ouvidos, seduzindo a alma em uma vibratilidade expansiva de verdade, de coloridoò(MARCOS, 1892, p. 1).

Dias depois, José Fino ${ }^{4}$ afirmaria em $O$ País ter encontrado na obra do ñevolucionário da poesia portuguesaò, isto é, Guerra Junqueiro ñum lirismo encantador, uma suavidade bucólica, sem banalidades choramingasò (FINO, 1892, p. 1). Cabe observar que o adjetivo ñevolucionárioò se aplicava muito mais ao impiedoso crítico da sociedade portuguesa, que escreveu A morte de D. João e A velhice do Padre Eterno, do que ao ousado nefelibata de Os simples.

Em 4 de julho, José Antônio de Freitas, ${ }^{5}$ correspondente lisboeta do Jornal do Comércio que se assinava como Raul, tratou de Os simples em duas colunas e meia do seu rodapé. Era, em sua opinião, ñao mesmo tempo a obra de um pensador e de um homem de letrasò. Guerra Junqueiro teria pretendido nela representar a ñvida singela e primitivaò de ñboas e santas criaturasò, encarnando em um ñcerto número de personagensò como um pastor, a moleirinha, o cavador etc. Tal representação teria sido, porém, coordenada pelo ñponto de vista particularò ou pelo ñestado de consciênciaò do artista, o qual, assim, se confundia com suas personagens (RAUL, 1892, p. 1). Na verdade, Raul apenas reproduzia, essencialmente, considerações tecidas pelo próprio Junqueiro na ñNotaò que acrescentou à sua obra.

Redator anônimo do jornal $O$ Tempo ainda em 4 de julho encareceu a qualidade material do livro, que era impresso ñno mais alvo, no mais cantante, no mais puro papel de linho que é dado fabricarò (OS SIMPLES, 1892, p. 1), mas não associou tal característica ao nefelibatismo, embora o aspecto e o material das capas e do papel fossem sabidamente uma questão de suma importância para os autores próximos ao decadentismo-simbolismo.

No Diário de Notícias de 8 de julho, Somel ${ }^{6}$ vinculou pela primeira vez Os simples aos nefelibatas ou simbolistas, pois estes, que pretendiam ñmudar o ritmo graciosamente musical do versoò, poderiam encontrar nos versos de Junqueiro ñargo pasto às suas repetições monótonasò. $\mathrm{O}$ cronista considerou que a nova obra talvez correspondesse, na vida

\footnotetext{
${ }^{4}$ Provável pseudônimo. Ignora-se a quem pertencia.

${ }^{5}$ Nascido no Maranhão, Freitas mudou-se ainda criança para Portugal, onde viveu o resto da vida. Em Lisboa, foi professor da Escola Acadêmica.

${ }^{6}$ Ignora-se a identidade de quem utilizava esse pseudônimo.
} 


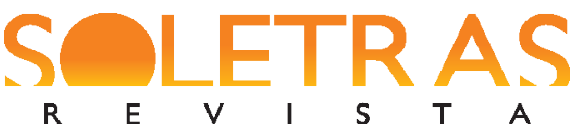

do poeta, que envelhecia, à ñdescida por um doloroso obumbramento de cérebroò, ou seja, ao início da decadência física e mental. Refutou, porém, a hipótese de imediato por acreditar que, na ñopulenta vida literáriaò de Junqueiro, Os simples não passaria de ñdesastrado parêntesisò (SOMEL, 1892, p. 1). Conclui-se, portanto, que Somel não era favorável às obras nefelibatas e as tomava por manifestações do esteticismo decadentista. ${ }^{7}$

Havia, no entanto, quem exaltasse a obra. Em 12 de julho de 1892, nas Novidades, D. Marcos considerou brevemente Os simples, ao lado de o romance La débacle, de Zola, como um dos pontos culminantes do ano literário então em curso (MARCOS, 1892, p. 1).

Dias depois, ocupou-se do livro em $O$ País, sob o pseudônimo de Caliban, Coelho Neto, que iniciou seu texto com referências irônicas ao trabalho da crítica, garantiu depois ser o novo livro ñmais do que uma grande pastoral em que toma[va]m parte promiscuamente seres e coisasò e alertou, por fim, que deveria ser lido como a expressão alegórica da vida e dos sentimentos do poeta. Em sua avaliação, essencialmente positiva, não se associaram as ñestrofes maviosíssimasò do livro ao nefelibatismo ou decadentismo (CALIBAN, 1892, p. 1). Logo no início do ano seguinte, Coelho Neto escreveria texto satírico a respeito do Missal, de Cruz e Sousa (RIBAS, 1893, p. 1), autor que, no Brasil, representava as novas tendências literárias de então.

Caberia à portuguesa Maria Amália Vaz de Carvalho, correspondente do Jornal do Comércio, publicar em 24 de julho o primeiro texto crítico mais alentado sobre Os simples. Segundo ela, os ñartifícios literáriosò de origem decadentista-simbolista Guerra Junqueiro não os devia aos nefelibatas portugueses, ao contrário do que estes proclamavam, mas, por ñfraquezaò, à ñescola artificialò de Verlaine e outros franceses, o que, entretanto, não punha em risco a sua individualidade artística (CARVALHO, 1892, p. 2). Com essas palavras provavelmente referia-se à tentativa, perpetrada por Alberto de Oliveira, de anexação de Junqueiro ao grupo neogarrettiano, que pretendia dar uma guinada nacionalista à literatura portuguesa. Tal propósito podia ser constatado na resenha de O livro de Aglaïs, de Júlio Brandão, publicada nas Novidades, de Lisboa, em 28 de abril de 1892 (OLIVEIRA, 1892, p. $3)$.

Considerando Os simples um ñpoema das almas humildes, rudimentais, que vivem em contato direto com a naturezaò, a cronista exaltou as qualidades e lamentou os defeitos dos

\footnotetext{
${ }^{7}$ Cabe esclarecer que diferentes termos, tais como decadismo, decadentismo, simbolismo, nefelibatismo e novismo foram empregados para designar a poesia nova do final do século XIX.
} 


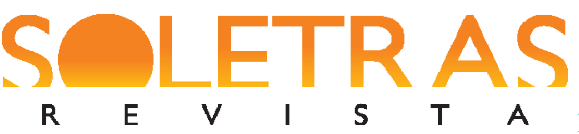

principais poemas reunidos no volume. Quanto às deficiências, observou que o ritmo empregado uniformemente ñsem variedade acaba finalmente por ser monótono e às vezes impróprio para a poesiaò e que a filosofia do poeta era constituída de ñfragmentos desconexosò de matriz naturalista e panteísta. Ocasionais ñdeclarações jacobinasò e ñceticismos voltairianosò permitiram à cronista ressaltar a contraditória presença, no espírito do poeta, de 1) um ñmisticismo ingênito que [...] o inspira[va] quase sempreò, por ñatavismo religiosoò, 2) a ñironia adquiridaò e 3) a ñdúvida mordaz que esteriliza[va] tanta vez a sua sensibilidadeò (CARVALHO, 1892, p. 2).

A cronista colocou também em dúvida a verossimilhança ou coerência interna das personagens rústicas criadas por Junqueiro. Segundo ela, Junqueiro não poderia ter encontrado ñas províncias portuguesasò o amor que o montanhês de In pulvis, segunda parte do poema intitulado ñCadáverò, demonstrava pelo castanheiro, evocando, diante da lareira onde ardia lenha fornecida pela árvore morta, ñtodas as cenas do passadoò de que ela tomara parte. A respeito do poema ñO cavadorò, julgou que a revolta e a tristeza manifestadas pelo trabalhador rural pertenciam muito mais ao poeta do que a sua personagem: ñDeu [Junqueiro] a sua consciência, a sua revolta, o seu sentimento das desigualdades sociais a rude filho da terra ...ò(CARVALHO, 1892, p. 2).

A propósito das queixas melancólicas do poema ñRegresso ao larò, Maria Amália Vaz de Carvalho concedeu, acacianamente, que ña vida é tristeò, mas exortou o poeta a não ñmaldizê-laò porque era, com seu talento, ñum dos seus raros eleitosò. A partir daí, sucederam-se em cascata generosos conselhos a Guerra Junqueiro, que devia desvencilhar-se da ñironia esterilizanteò, identificar-se com a ñNaturezaò, tornar-se como ela ñmultiformeò e ñmulticoròe limitar-se ao ñmistério das cousas, insondável e sagradoò, abdicando de procurar conhecer ño princípio e o fim dos fenômenosò à sua volta, com o que iria fatalmente conquistar ñaquela suprema tranquilidade, aquela serena paz quase divina que caracterizam os poetas genuínosò. Além disso, devia o poeta evitar as ñdeclarações jacobinas contra o Catolicismoò, as ñnotas em prosaò acrescentadas aos versos e outras humilhantes ñtransigênciasò e ñdoutrinasò consideradas pela cronista ñmesquinhas, limitadas e convencionaisò (CARVALHO, 1892, p. 2). Aludia assim a cronista aos traços mais evidentes de nefelibatismo que se notavam no livro, mas com o objetivo de refutá-los por equivocados. 


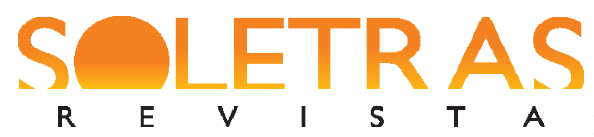

Maria Vaz de Carvalho encerrou o seu longo artigo conclamando Guerra Junqueiro a deixar ñgrasnar [...] a vaidade das rãsò e ñivar a inveja das hienasò, pois havia escrito ñum belo e grande livroò (CARVALHO, 1892, p. 2). Apesar da relativa boa recepção por parte da imprensa portuguesa, Os simples recebeu críticas, algumas das quais contundentes. Seria, no entanto, razoável supor, como fazia a cronista, que tais objeções ao livro podiam ter sido motivadas por ressentimentos pessoais e/ou antagonismos partidários, haja vista a intensa atuação política do autor.

Domício da Gama, brasileiro que de Paris enviava textos para a Gazeta de Notícias, tratou abertamente, em 28 de julho, da questão da alegada precedência de Os simples em relação aos demais livros nefelibatas. Para o cronista, Os simples, antes mesmo de sua publicação, era do conhecimento de outros escritores, que quase ñapanharam a toadaò do livro ao ouvir declamações do autor (GAMA, 1892, p. 1). Confirmava assim o correspondente da Gazeta de Notícias as alegações de pioneirismo que constavam da ñNotaò adicionada por Junqueiro ao final do seu livro.

Domício da Gama discutiu também as pretensões totalizantes de Junqueiro, que assegurava ter alcançado ñdo universo uma ideia metódica e definitivaò e pretendeu escrever, apesar da aparência bucólica do livro, uma ñautobiografia psicológicaò. O cronista não levou a sério tais pretensões, que, para ele, se desvaneciam diante da emoção suscitada pelos versos: ñNão há sistema, não há símbolo, não há metafísica que nos desfaça a emoção pura dos versos puríssimos e simplesò (GAMA, 1892, p. 1). Dessa forma, o cronista deslocava para um segundo plano as pretensões totalizantes que Junqueiro evidenciou na nota final do livro.

Na edição de julho de 1892 da Revista Acadêmica da Faculdade Livre de Direito, um certo M. comentou brevemente em sua crônica mensal o livro de Junqueiro, cuja imaginação seria ñfonte límpida de ideias brilhantes e cristalinas, que [...] trasladava para o papel com a forma mais simples e deliciosa possívelò. Não foi o cronista além desses elogios convencionais, mas considerou Os simples a ñperfeição últimaò no ñdificílimo gêneroò da poesia bucólica (M., 1892, p. 16).

Em $O$ País, edição de 16 de agosto, o correspondente lisboeta Pinheiro Chagas dedicou-se exclusivamente a Os simples. Iniciou-se o longo artigo com apreciação do livro de Guerra Junqueiro, escrita, segundo Chagas, ñao correr da penaò e já divulgada no Correio da Manhã, de Lisboa, em 3 de junho. Nessa primeira parte, havia breves considerações sobre 


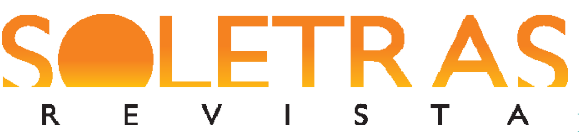

vários poemas do livro, mesclando-se elogios e reparos críticos. Embora reconhecesse que $O s$ simples possuíam ñpáginas verdadeiramente admiráveisò, começou por observar que ñfatiga[va] às vezes um poucoòa ñ̃epetição quase incessante do mesmo ritmoò, problema que já fora acremente apontado por Armando Navarro nas Novidades, de Lisboa, no dia 2 de junho. Depois de dizer que se entusiasmara com o r̃̃relúdioò, afirmou que Junqueiro quis, com a ñA moleirinhaò, provar que, ao ñfazer nefelibatismoò, o fazia ñmelhor que todos os outros juntosò. Deste poema, cita versos em que se atribuem pensamentos a um burrico, para quem as estrelas eram ñmilho loiroò e a lua, ñmó de jaspeò (CHAGAS, 1892, p. 1). O trecho suscitou comentário sarcástico de Chagas:

O Sr. Eugênio de Castro fez da lua peneira, o Sr. Antônio Nobre leiteira, ${ }^{8}$ o Sr. Guerra Junqueiro mó de moinho. A noite para o Sr. Eugênio de Castro é padeira, para o Sr. Antônio Nobre dona de uma vacaria, para o Sr. Guerra Junqueiro moleira.

Pobre noite! E pobre lua! Caíram em boas mãos! (CHAGAS, 1892, p. 1)

Se para o correspondente estrangeiro do matutino carioca $O$ País o poema ño cadáverò era ñadmirávelò; ñErmidasò, ñencantadorò, e ñO pastorò, uma ñobra-primaò; o ñCampo santoò não passava de uma ñestopadaò. Já ño cavadorò, que considerou uma ñpoesia dilacerante de tomò, ficaria prejudicado pelo cansaço proporcionado pelo ñdobre de sinos constanteò do restante do livro. Para Chagas, o poema ñEpílogoò seria ñsoberbíssimoò; dele transcreveu uma estrofe que o teria feito ñcorrer as lágrimas de um modo irresistívelò (CHAGAS, 1892, p. 1).

$\mathrm{Na}$ continuação escrita exclusivamente para seus leitores brasileiros, o cronista desenvolveu um pouco mais a comparação entre o ñPrelúdioò poema de abertura, e o ñEpílogoò. Chagas condenou a solução alegórica adotada para o primeiro, porque, em sua opinião, ñquando um poeta de gabinete, um épico erudito, ainda que se chame Virgílio, começa a fazer esforços para criar alegorias, para transformar em entes que a sua fantasia

\footnotetext{
${ }^{8}$ Pinheiro Chagas alude às Horas, de Eugênio de Castro, onde se lê: ñ̃E a Padeira-Noite põe-se a peneirar / Na peneira-Lua a farinha-Luarò (CASTRO, 1891: 21). No caso de Antônio Nobre, refere-se ao primeiro terceto do poema ñ Ca(ro) Da(ta) Ver(mibus)ò, que consta da primeira edição do Só (1892: 126-31). Os versos de Nobre são os seguintes: ñÀs horas do crepúsculo, ao Bendito, / Quando a formosa Lua, a leiterinha, / Vai dar o leite às casas do Infinito...ò
} 


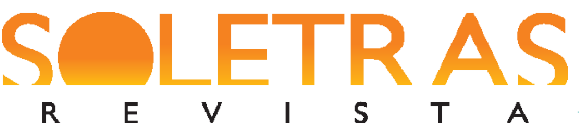

laboriosamente fabrica os seres da vida real, os sentimentos da sua alma, nada há mais fatigador e mais fastidiosoò (CHAGAS, 1892, p. 1).

Após prever que Junqueiro ainda seria reconhecido como ñum dos grandes poetas portuguesesò do século XIX, que de A morte de D. João e A velhice do Padre Eterno sobreviveriam ñargos trechosò do ñaufrágioò do conjunto e que de A musa em férias e $O s$ simples seria extraída uma ñseletaò destinada a ñencantarò os pósteros, Chagas acusou o poeta de escrever $A$ moleirinha por não gostar de ser precedido por ñinovadores de qualquer espécieò, por receio de ser considerado ñfora de modaò, por temer que o público abandonasse Os simples para ñse extasiar com as audácias do Só, de Antônio Nobreò, e por não se conformar com ñum passageiro eclipse da popularidade que o inebria[va]ò (CHAGAS, 1892, p. 1). Dessa forma, Pinheiro Chagas atribuía razões recônditas e pouco nobres para as alegações de precedência contidas na ñ̃Notaò final do volume, ñescrita rapidamente, à última hora, com o impressor à esperaò (JUNQUEIRO, 1892, p. 126), como confessou o próprio poeta. O poeta não queria que jovens até então pouco conhecidos viessem empanar o seu esplendor (v. figura 2).

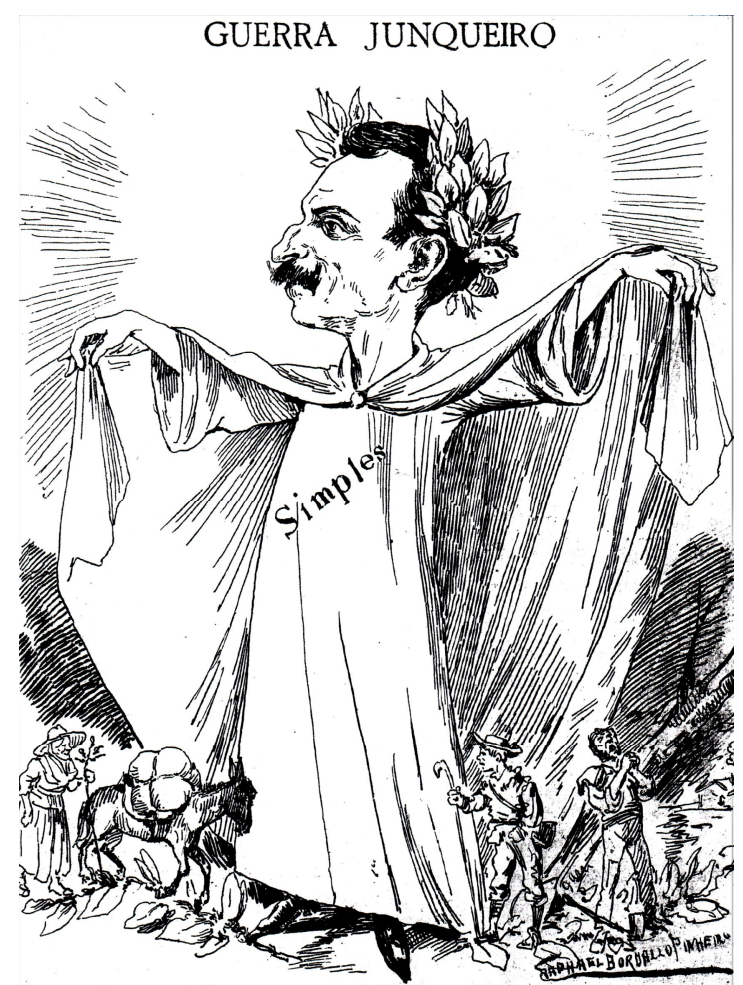

Fig. 2 Charge de Guerra Junqueiro por Rafael Bordalo Pinheiro publicada na página 475 da Revista Ilustrada $O$ Antônio Maria em 4 de junho de 1892. 


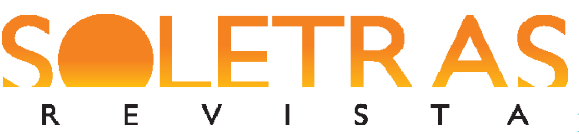

N. 40 ï 2020.2 ï ALVARO SANTOS SIMÕES JUNIOR

No fragmento final de seu texto, o cronista tomou o poema Cadáver como indício de inflexão no espírito do poeta, que, invadido por um ñsopro panteísticoò, já não seria capaz de escrever o prometido livro A morte de Jeová, que constava de lista de obras a publicar divulgada com $A$ velhice do Padre Eterno. Ficaria assim incompleta a trilogia demolidora iniciada com A morte de D. João. Não era ainda, assegurou Chagas, a conversão completa do poeta ao catolicismo, mas indicação de que sua alma se voltava, ñcompungida e anelante, para os ideais da crença, ainda vaga e indefinidaò (CHAGAS, 1892, p. 1).

No melhor texto publicado sobre o decadentismo-simbolismo na imprensa carioca, estampado na edição de 29 de dezembro de $O$ País, o português imigrado Crispiniano da Fonseca, que viria a morrer de febre amarela no Brasil, citou versos de Os simples ao dissertar com muita competência sobre as características formais da poesia nefelibata (FONSECA, 1892, p. 1). Nas suas ñLériasò, que assinava com as iniciais C. F., o cronista narrou em 13 de janeiro de 1893 encontro com Guerra Junqueiro no Porto, um ano antes. Naquela ocasião, o poeta lhe confessara ter ñenfim conseguido achar uma compreensão filosófica superior do universo, para a qual ia escrever a epopeia própriaò. Com Os simples, que seriam essa ñepopeiaò, pretendia, sem nenhuma modéstia, imprimir ñuma revolução completa à estética contemporâneaò(F., 1893, p. 1). Esse breve relato demonstrava que, desde o início, Junqueiro estava convicto de que Os simples seriam uma obra marcante da literatura portuguesa e conteriam muito mais do que lirismo bucólico.

À guisa de conclusão, pode-se afirmar que Os simples foi a obra nefelibata mais lida e comentada no Brasil no primeiro momento da difusão das ideias decadentistas-simbolistas. A repercussão da obra de Guerra Junqueiro foi favorecida por dois favores identificados pela pesquisa: a venda promovida pela livraria Garnier, que chegou a publicar anúncios do livro na imprensa carioca, e o prestígio do escritor, consolidado com a obra sobre a seca no Ceará e as sátiras de conteúdo político-ideológico, que circularam no período em que as campanhas da Abolição e da mudança de regime chegavam ao seu ápice.

Constata-se, também, que já havia relativo entrelaçamento entre os mercados editoriais brasileiro e português, pois os exemplares de Os simples chegaram simultaneamente às vitrinas de livrarias cariocas e lisboetas. 


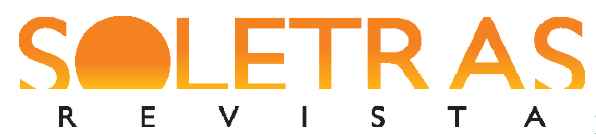

Observa-se nas notícias e resenhas que a ñNotaò escrita às pressas e adicionada por Guerra Junqueiro ao final do seu livro condicionou as primeiras leituras, mas a questão de sua filiação às modernas tendências poéticas não foi abordada por todos os autores dos textos encontrados durante a pesquisa. Curiosamente, Coelho Neto, que escreveria sátira contra Cruz e Sousa, não criticou Guerra Junqueiro por suas ostensivas concessões ao decadentismosimbolismo. A complacência com o poeta português resultava do respeito por ele, do temor de sua verve satírica, tantas vezes manifestada em poemas de circunstância, da não percepção do nefelibatismo difuso em Os simples ou do fato de que Junqueiro não era para o grupo de Coelho Neto, a rigor, um ñconcorrenteò, como poderia vir a ser Cruz e Sousa? É difícil hoje responder com segurança a essa questão.

Maria Amália Vaz de Carvalho escreveu a maior resenha a respeito de Os simples, isolando Guerra Junqueiro dos nefelibatas e associando-o diretamente a Verlaine e a outros decadentistas-simbolistas franceses. Porém, criticou seu compatriota por suas contradições temáticas e ideológicas e condenou a inverossímil construção das personagens rústicas por Junqueiro, pois estas, em sua opinião, resultariam muito mais da projeção da personalidade do poeta do que da observação da realidade social do campo português.

Sempre cordial e até mesmo simpática, Maria Amália Vaz de Carvalho aconselhou o poeta a deixar o radicalismo ideológico, o pessimismo convencional e as ousadias formais, mas o defendeu de críticas impiedosas e mal-intencionadas que derivavam das paixões políticas despertadas pelo intenso ativismo de Junqueiro, deputado e crítico da realidade portuguesa, que àquela altura estava próximo dos círculos republicanos.

Pinheiro Chagas pouco acrescentou de essencial às críticas formuladas por outros jornalistas e colaboradores eventuais da imprensa carioca, mas atribuiu perfidamente o nefelibatismo adotado em Os simples a motivações subalternas e mesquinhas. Do seu ponto de vista ferino, Guerra Junqueiro, por vaidade, simplesmente temia ser superado pelos novos poetas que surgiam.

Chagas, no entanto, formulou crítica pertinente à forma alegórica do poema Prelúdio. Considerou-a contrária à expressão lírica por ser artificiosa e consequentemente causar fastio. Monarquista e católico, o correspondente estrangeiro do jornal $O$ País também comemorou o conteúdo espiritualizante da obra, que poderia indicar inflexão filosófica ou religiosa por parte do poeta. 


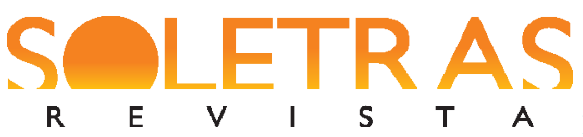

Por fim, o português Crispiniano da Fonseca confirmou, com seu testemunho, que Junqueiro tinha grandes pretensões quando escreveu Os simples, obra que deveria conter uma visão totalizante da vida e, além disso, apontar novos rumos para a literatura portuguesa. No Brasil, pelo menos, atribuiu-se ao livro maior relevância do que teve, de fato, no decadentismo-simbolismo português, levando provavelmente a uma compreensão do movimento enviesada e fragmentária por parte de leitores e críticos brasileiros.

\section{Referências}

A Revista ilustrada. Diário de Notícias, Rio de Janeiro, p. 2, 3. col., 26 ag. 1892.

ALMEIDA, Padre José Joaquim Correa de. O Apóstolo, Rio de Janeiro, p. 3, 1. col., 4 jan. 1893.

CALIBAN [pseudônimo de Coelho Neto]. Palestra. A propósito dos ñ́simplesò. O País, Rio de Janeiro, p. 1, 1.-2. col., 17 jul. 1892.

CARVALHO, Maria Amália Vaz de. Os simples. A poesia contemporânea ï Guerra Junqueiro. Jornal do Comércio, Rio de Janeiro, p. 2., 3.-6. col., 24 jul. 1892.

CASTRO, Eugênio de. Horas. Coimbra: Manuel de Almeida Cabral, 1891.

CHAGAS, Pinheiro. Simples. O País, Rio de Janeiro, p. 1, 1.-2. col., 16 ag. 1892.

F., C. [Crispiniano da Fonseca] Lérias. Guerra Junqueiro. O País, Rio de Janeiro, p. 1, 6. col., 13 jan. 1893.

FINO, José. Reminiscências. O País, Rio de Janeiro, p. 1, 1.-2. col., 27 jun. 1892.

FONSECA, Crispiniano da. Decadismo. O País, Rio de Janeiro, p. 1, 1.-3. col., 29 dez. 1892.

GAMA, Domício da. Os simples. Gazeta de Notícias, Rio de Janeiro, p. 1, 6.-7. col., 28 jul. 1892.

GOMES, Gualdino; SERTÓRIO, Carlos. Guerra Junqueiro está escrevendo... Balas... de Papel, Lisboa, v. 2, p. 10, 15 dez. 1891.

GUERRA Junqueiro, o grande poeta português... Correio Português, Rio de Janeiro, p. 2, 4. col., 13 jan. 1892.

GUERRA Junqueiro... O País, Rio de Janeiro, p. 4, 6. col., 18 set. 1892.

GUERRA Junqueiro... O País, Rio de Janeiro, p. 5, 1. col., 14 set. 1892. 


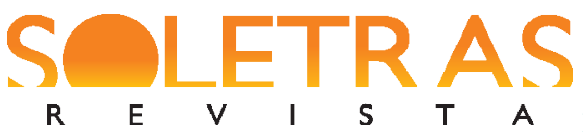

GUERRA Junqueiro... O País, Rio de Janeiro, p. 6, 2. col., 16 set. 1892.

JOB, Máximo. Ecos da cidade. O Tempo, Rio de Janeiro, p. 1, 3.-4. col., 17 ag. 1892.

JUNQUEIRO, Guerra. Os simples. Porto: Tipografia Ocidental, 1892.

M. A crônica. Revista Acadêmica da Faculdade Livre de Direito, Rio de Janeiro, p. 16, 1.-2. col., jul. 1892.

MARCOS, D. Palestra. Novidades, Rio de Janeiro, p. 1, 3. col., 18 jun. 1892.

. Palestra. Novidades, Rio de Janeiro, p. 1, 3. col., 12 jul. 1892.

. Palestra. Novidades, Rio de Janeiro, p. 1, 5. col., 13 jul. 1892.

MODESTO, Álvaro. Os simples. Novidades, Rio de Janeiro, p. 1, 6.-7. col., 12 jul. 1892.

NAVARRO, Armando. Os simples por Guerra Junqueiro. Novidades, Lisboa, p. 3, 1.-2. col., 2 jun. 1892.

NOBRE, Antônio. Só. Paris: Léon Vanier, 1892.

OLIVEIRA, Alberto de. O livro de Aglaïs por Júlio Brandão. Novidades, Lisboa, p. 3, 4. col., 28 abr. 1892.

OS SIMPLES. Gazeta de Notícias, Rio de Janeiro, p. 1, 5. col., 30 jun. 1892.

OS SIMPLES. O Tempo, Rio de Janeiro, p. 1, 6.-7. col., 4 jul. 1892.

OS SIMPLES. Revista Ilustrada, Rio de Janeiro, n. 646, p. 6, jun. 1892.

POR TODO o mês de outubro... O Tempo, Rio de Janeiro, p. 1, 4. col., 14 set. 1891.

RAUL [pseudônimo de José Antônio de Freitas]. O que vai por aí. Jornal do Comércio, Rio de Janeiro, p. 1, rodapé, 4 jul. 1892.

RIBAS, Anselmo [pseudônimo de Coelho Neto]. Inauditismo. O País, Rio de Janeiro, p. 1, 1. col., 5 mar. 1893.

SOMEL. Sala dôrmas. Os simples. Diário de Notícias, Rio de Janeiro, p. 1, 7. col., 8 jul. 1892.

\title{
Os simples by Guerra Junqueiro and the Brazilian press
}

\begin{abstract}
From 1890 to 1893, it took place in Portugal an intense literary movement as a result of assimilation of decadent-symbolist ideas emanating from France. In this period, sixteen works with innovative trends were published. In Rio de Janeiro, the press followed with little interest news and controversies motivated by publications and attitudes taken by Eugênio de Castro, Alberto de Oliveira, Antônio Nobre among other young writers. However, the decadent-symbolist work that most had aroused interest of Rio newspapers and magazines was Os simples, lyrical poetry published by veteran
\end{abstract}




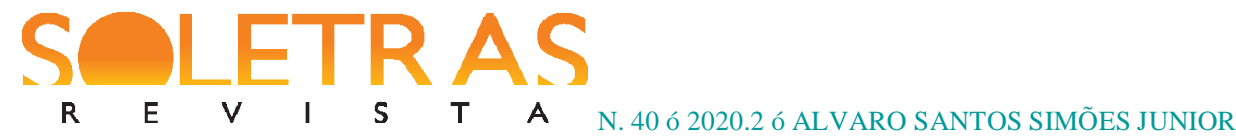

Guerra Junqueiro in 1892. The analysis of news, reviews and articles on this work makes possible to understand a little better how has occurred the assimilation of Decadence-Symbolism in Brazil.

Keywords: Decadence. Symbolism. Os simples. Guerra Junqueiro.

Recebido em: 15 de maio de 2020.

Aceito em: 18 de junho de 2020. 